\title{
MRI progression of cerebral small vessel disease and cognitive decline in patients with hypertension
}

Citation for published version (APA):

Uiterwijk, R., Staals, J., Huijts, M., de Leeuw, P. W., Kroon, A. A., \& van Oostenbrugge, R. J. (2017). MRI progression of cerebral small vessel disease and cognitive decline in patients with hypertension. Journal of Hypertension, 35(6), 1263-1270. https://doi.org/10.1097/HJH.0000000000001294

Document status and date:

Published: 01/06/2017

DOI:

10.1097/HJH.0000000000001294

Document Version:

Publisher's PDF, also known as Version of record

Document license:

Taverne

Please check the document version of this publication:

- A submitted manuscript is the version of the article upon submission and before peer-review. There can be important differences between the submitted version and the official published version of record.

People interested in the research are advised to contact the author for the final version of the publication, or visit the DOI to the publisher's website.

- The final author version and the galley proof are versions of the publication after peer review.

- The final published version features the final layout of the paper including the volume, issue and page numbers.

Link to publication

\footnotetext{
General rights rights.

- You may freely distribute the URL identifying the publication in the public portal. please follow below link for the End User Agreement:

www.umlib.nl/taverne-license

Take down policy

If you believe that this document breaches copyright please contact us at:

repository@maastrichtuniversity.nl

providing details and we will investigate your claim.
}

Copyright and moral rights for the publications made accessible in the public portal are retained by the authors and/or other copyright owners and it is a condition of accessing publications that users recognise and abide by the legal requirements associated with these

- Users may download and print one copy of any publication from the public portal for the purpose of private study or research.

- You may not further distribute the material or use it for any profit-making activity or commercial gain

If the publication is distributed under the terms of Article $25 \mathrm{fa}$ of the Dutch Copyright Act, indicated by the "Taverne" license above, 


\title{
Original Article
}

\section{MRI progression of cerebral small vessel disease and cognitive decline in patients with hypertension}

\author{
Renske Uiterwijk ${ }^{a, b}$, Julie Staals ${ }^{a, c}$, Marjolein Huijts ${ }^{d}$, Peter W. de Leeuw ${ }^{c, e, f}$, \\ Abraham A. Kroon ${ }^{c, e}$, and Robert J. van Oostenbrugge ${ }^{a, b, c}$
}

Objective: Hypertension is associated with cognitive deficits, probably because it is a major risk factor for the development of white matter hyperintensities $(\mathrm{WMH})$, lacunes, and cerebral microbleeds, which are MRI markers of cerebral small vessel disease. Studies into associations between presence or progression of these MRI markers and cognitive decline in hypertensive patients are rare. We investigated the association of baseline presence and progression of MRI markers of cerebral small vessel disease with cognitive decline over 4 years in patients with hypertension.

Methods: In this longitudinal study, hypertensive patients underwent neuropsychological assessments and brain MRI at baseline and after 4 years. Presence and progression of periventricular and subcortical WMH, lacunes, and cerebral microbleeds were visually rated.

Results: In total, 128 hypertensive patients (90 patients with essential hypertension and 38 hypertensive lacunar stroke patients), mean age: $58.6 \pm 12.2$ years, were included. Progression of periventricular WMH was associated with cognitive decline in simple regression analysis $(P=0.001)$ and in multivariable analysis with correction for baseline WMH presence and potential confounders $(P=0.004)$. In this multivariable analysis, $R^{2}$ of progression of periventricular WMH was $5.6 \%$, whereas $R^{2}$ of baseline presence of periventricular $\mathrm{WMH}$ was $0.6 \%$. We did not find significant associations between baseline presence or progression of the other MRI markers and cognitive decline.

Conclusion: In patients with hypertension, progression of periventricular WMH over 4 years is associated with cognitive decline, whereas we could not show an association between baseline periventricular $\mathrm{WMH}$ and cognitive decline. These results emphasize the importance of preventing progression of $\mathrm{WMH}$ in hypertensive patients.

Keywords: cerebral microbleeds, cognitive decline, hypertension, lacunes, small vessel disease, white matter hyperintensities

Abbreviations: cSVD, cerebral small vessel disease; HADS, Hospital Anxiety and Depression Scale; SCWT, Stroop Colour Word Test; TMT, Trail Making Test; WAIS-III, Wechsler Adult Intelligence Scale-III; WMH, white matter hyperintensities

\section{INTRODUCTION}

$\mathrm{H}$ ypertension is a risk factor for cognitive deficits and vascular dementia, probably because hypertension induces microvascular dysfunction in the brain [1]. This leads to brain damage, such as white matter hyperintensities (WMH), lacunes, and cerebral microbleeds. These are MRI markers of cerebral small vessel disease (CSVD).

Cross-sectional studies have shown that the MRI markers of CSVD are associated with lower cognitive functioning [26]. The implications of these MRI markers on future cognitive decline have been investigated less extensively, but a number of studies have shown that the presence of MRI markers predicts cognitive decline [7-9]. Only a few studies have investigated the increase or progression of MRI markers in relation to cognitive decline longitudinally. Associations between WMH progression and cognitive decline have been shown [10-13]. However, most of the studies did not differentiate between periventricular and subcortical/deep WMH, despite the fact that cross-sectional data showed that location of WMH might influence the impact on cognition $[2,14,15]$. In addition, only very few studies have shown associations between new lacunes $[10,16,17]$ or microbleeds [18] and cognitive decline. Finally, it is unclear whether the progression of SVD is more predictive of cognitive decline than the presence of SVD at baseline.

Most of these earlier studies were population studies. The association between progression of SVD and cognitive decline has not been assessed before specifically in hypertensive patients, even though it is known that high blood pressure (BP) is associated with an increased risk for

Journal of Hypertension 2017, 35:1263-1270

aDepartment of Neurology, Maastricht University Medical Centre, ${ }^{b}$ School for Mental Health and Neuroscience (MHeNs), Maastricht University, ' $C$ ardiovascular Research Institute Maastricht (CARIM), Maastricht University, ${ }^{\mathrm{d}}$ Department of Psychiatry and Psychology, Maastricht University Medical Centre, 'Department of Internal Medicine, Maastricht University Medical Centre, Maastricht and ${ }^{f}$ Department of Internal Medicine, Zuyderland Medical Centre, Sittard/Heerlen, the Netherlands

Correspondence to Renske Uiterwijk, Department of Neurology, Maastricht University Medical Centre, P. Debyelaan 25, P.O. Box 5800, 6202 AZ Maastricht, the Netherlands. Tel: +31 43387 1178; fax: +31 43387 7055;

e-mail: renske.uiterwijk@mumc.nl

Received 20 October 2016 Revised 23 December 2016 Accepted 13 January 2017 J Hypertens 35:1263-1270 Copyright (C) 2017 Wolters Kluwer Health, Inc. All rights reserved.

DOI:10.1097/HJH.0000000000001294 
developing SVD [19] and with progression of MRI markers [20]. More insight into predictors of cognitive decline in this population at risk is needed. Therefore, the aim of the present study was to investigate the association of both baseline presence and progression of MRI markers of cSVD with cognitive decline over 4 years in patients with hypertension.

\section{METHODS}

\section{Study population}

To have a wide range of severity of CSVD on MRI, we included both uncomplicated hypertensive patients, and hypertensive patients who had suffered a lacunar stroke because of cSVD. Patients were selected from two larger studies: uncomplicated hypertensive patients from the hypertension and brain damage study (HYBRiD) [21] and hypertensive lacunar stroke patients from the cognitive function in small vessel stroke study [22].

In the HYBRiD study, essential hypertensive patients were recruited from the hypertension outpatient clinic of the Department of Internal Medicine of Maastricht University Medical Centre, the Netherlands. Hypertension was defined as an off medication, office measured conventional $\mathrm{BP}$ of at least $140 \mathrm{mmHg}$ SBP and/or at least $90 \mathrm{mmHg}$ DBP. Exclusion criteria were a history of symptomatic cardio or cerebrovascular disease or contraindications for MRI. Details about the HYBRiD study have been described before [21]. A total of 218 patients were included in the HYBRiD study and they were asked to participate in the present follow-up study.

In the cognitive function in small vessel stroke study, first-ever lacunar stroke patients were recruited from the Neurology Department of the Maastricht University Medical Centre between February 2009 and July 2012. Lacunar stroke was defined as an acute stroke syndrome with a small $(<20 \mathrm{~mm})$ noncortical ischemic lesion on acute brain MRI, compatible with the occlusion of a single perforating small artery. If no such lesion was visible, we used established clinical criteria for lacunar stroke [23]. Patients with severe comorbidity, either neurological or psychiatric, were excluded. Furthermore, patients with possible other causes for the lacunar stroke than cerebral SVD (cardiac embolic source, cerebral large vessel disease, or carotid stenosis), were also excluded [22]. A total of 77 patients were included in the small vessel stroke study, and those who had hypertension (defined as the use of antihypertensive medication or a history of hypertension) were selected for the present study and asked for follow-up.

All patients underwent a brain MRI scan and a neuropsychological assessment, which were repeated after 4 years. For hypertensive lacunar stroke patients, the baseline neuropsychological assessment was performed 3 months after stroke to exclude acute phase effects. Registration of educational level was based on the Dutch classification system 'Verhage' (in which level 1, 2, 3, and 4 are considered as low education, level 5 is considered as middle education, and level 6 and 7 are considered as high education) [24]. Information about vascular risk factors [BMI, smoking, and the presence of diabetes mellitus or hypercholesterolemia (defined as the use of lipid-lowering drugs and/or a known total cholesterol level $>5.0 \mathrm{mmol} / 1$ for lacunar stroke patients or $>6.5 \mathrm{mmol} / 1$ for uncomplicated hypertensive patients)] was obtained. At follow-up, three automatic, oscillometric office BP measurements were taken in sitting position, after $10 \mathrm{~min}$ of rest and with 5 min between each measurement. Mean SBP and DBP was calculated by averaging the second and third measurements.

The Medical Ethics Committee of the Maastricht University Medical Centre approved this study and all participants gave written informed consent.

\section{MRI data}

All uncomplicated hypertensive patients were scanned twice on a $1.5 \mathrm{~T}$ MRI scanner, whereas the lacunar stroke patients were scanned twice using a $1.5 \mathrm{~T}$ or a $3 \mathrm{~T}$ scanner (both scanners: Philips Medical Systems, Best, the Netherlands). Patients were scanned at the same scanner at baseline and at follow-up. On brain MRI scans (standard axial T2-weighted, FLAIR, and T2* gradient echo sequences) two experienced vascular neurologists rated baseline MRI markers and one rated progression of markers, after reaching satisfactory interrater agreements. The interrater agreement statistics have been previously reported [22]. Baseline WMH was assessed according to the Fazekas scale [25]. Extensive periventricular WMH was defined as periventricular WMH Fazekas score 3 (irregular hyperintensities extending into the deep matter) and extensive subcortical/deep WMH was defined as deep WMH Fazekas score 2 or 3 (confluent hyperintensities). Lacunes and cerebral microbleeds were counted according to international consensus definition [26]. In lacunar stroke patients, the symptomatic lacunar infarct was not counted as lacune.

Progression of periventricular and subcortical WMH were scored according to the WMH change scale as proposed by Prins et al. [27]. Progression of periventricular WMH was scored in three regions (frontal caps, lateral band, and occipital caps) and progression of subcortical WMH is scored in four regions (frontal, parietal, temporal, and occipital). New lesions or increase of existing lesions was scored in each region as +1 and disappeared lesions or decrease of existing lesions was scored as -1 . This adds up to a progression score ranging from -3 to +3 for periventricular WMH and -4 to +4 for subcortical WMH. We defined progression of periventricular or subcortical WMH as a score of at least 1. Progression of lacunes or microbleeds was defined as any new lacune or microbleed.

\section{Neuropsychological assessment}

Cognitive performance was measured with a comprehensive neuropsychological assessment at baseline and after 4 years of follow-up, as has been described before [28]. Both patient groups received identical test protocols. Executive function domain was measured with the Stroop Colour Word Test [29] (SCWT) interference score (time of part 3-mean time of parts 1 and 2), Trail Making Test [30] (TMT) interference score (time of part B-time of part A), category (animals and professions) [31] and letter [32] verbal fluency, letter-number sequencing [subtest of Wechsler Adult Intelligence Scale (WAIS)-III] [33], and digit 


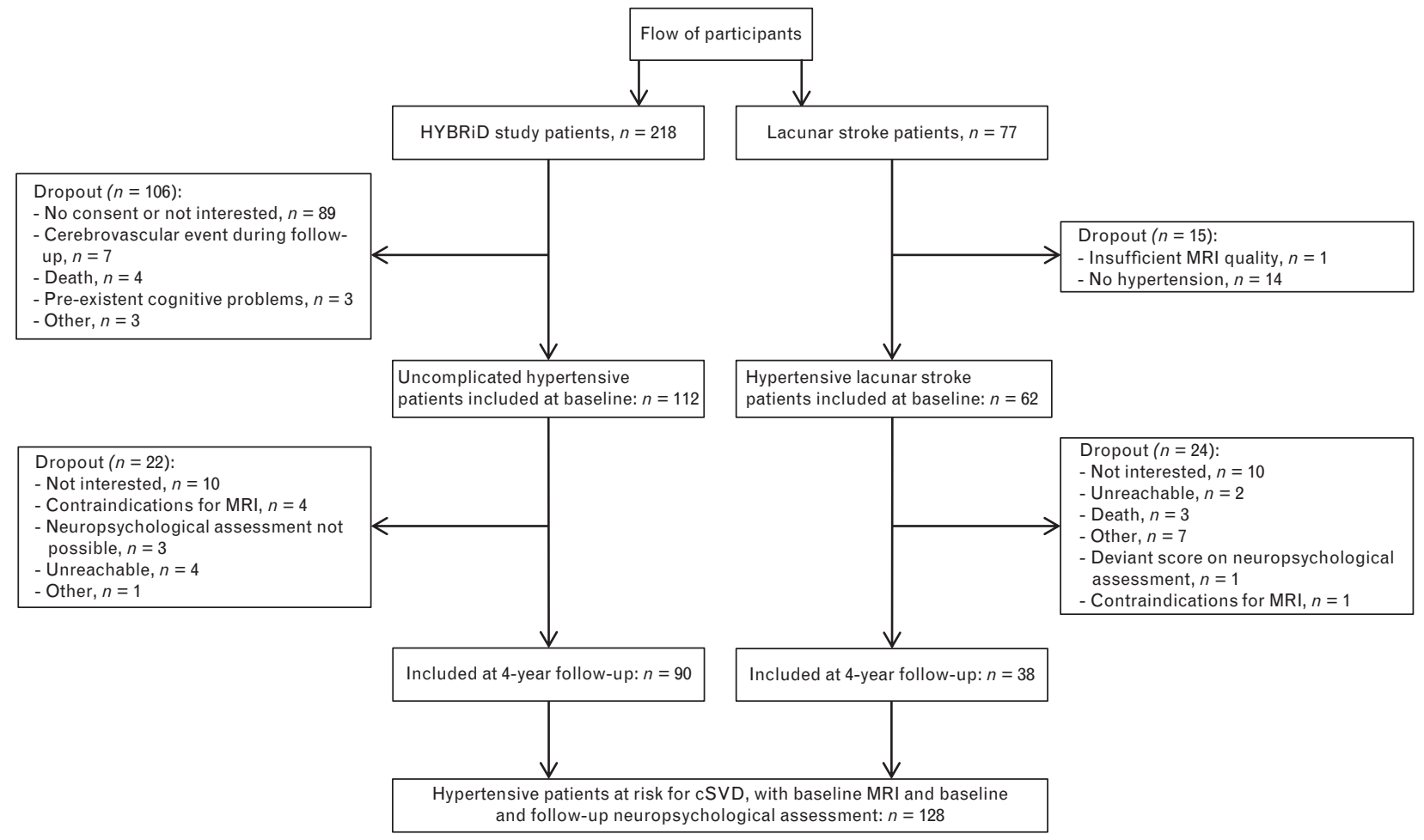

FIGURE 1 Participant flow diagram. CSVD, cerebral small vessel disease; HYBRiD, hypertension and brain damage study.

span backward (subtest of WAIS-III). Information processing speed domain was measured with the symbol substitution coding (subtest of WAIS-III), TMT part A, and SCWT parts 1 and 2. Memory domain was measured with the Rey Auditory Verbal Learning Test [34] (immediate recall, delayed recall, and delayed recognition) and the digit span forward (subtest of WAIS-III). Parallel versions were used for baseline and follow-up assessment for the Rey Auditory Verbal Learning Test and the letter fluency test.

For each patient, raw test scores at follow-up were subtracted from test scores at baseline. Standardized values ( $\mathrm{Z}$ scores) were created by dividing the difference between the individual raw score and the overall group sample mean by the overall group sample SD. Z scores of all tests within one domain were averaged to obtain cognitive decline compound scores of each domain. Next, the overall cognitive decline compound score was calculated by averaging the three domain compound scores. Higher compound scores indicated more decline. $\mathrm{Z}$ scores of tests with higher scores representing worse performance (e.g. SCWT and TMT) were inverted before computing the compound scores.

To determine the presence of possible dementia, the Rotterdam-Cambridge Cognitive Examination was used, in which a cut-off score of less than 34 was applied [35]. The Hospital Anxiety and Depression Scale (HADS) total score (range 0-42) was used to determine symptoms of depression and anxiety. As symptoms possibly caused by physical problems (e.g. insomnia or weight loss) are not included in the HADS, the scale is considered to be suitable to use in somatic populations [36].

\section{Statistical analysis}

Associations between baseline MRI markers and progression of MRI markers of SVD, and cognitive decline in overall cognition were investigated using simple linear regression analyses (model 1). Next, the associations of baseline MRI markers and progression of MRI markers with cognitive decline, independent of each other, were examined in a multivariable regression analyses (model 2). Model 2 was repeated for the two patient groups (uncomplicated hypertensive patient or hypertensive lacunar stroke patient) separately to examine if associations were similar in each group. Lastly, the associations were corrected for age, sex, educational level, HADS total score, patient group, baseline cognitive performance, and potential confounding vascular risk factors (BMI, smoking, the presence of diabetes mellitus or hypercholesterolemia, and SBP and DBP; model 3). To avoid overfitting, we only included those vascular risk factors that were associated with cognitive decline with $P<0.10$ in a simple regression model. In all models, besides the unstandardized regression coefficient, 95\% confidence interval (CI) and significance level, the $R^{2}$ was calculated to show the proportion of variance in cognitive decline explained by either the baseline MRI marker or the progression of MRI marker. The full multivariable regression model including all covariates (model 3) was repeated for the cognitive domains of executive functioning, information processing speed and memory.

IBM SPSS Statistics for Windows software (Version 22.0, IBM Corp., Armonk, New York, USA) was used for all analyses. Results were considered significant at $P<0.05$. 
TABLE 1. Patients' characteristics for uncomplicated hypertensive patients and hypertensive lacunar stroke patients

\begin{tabular}{|c|c|c|c|}
\hline Baseline characteristic & $\begin{array}{l}\text { All patients } \\
(n=128)\end{array}$ & $\begin{array}{c}\text { Uncomplicated hypertensive } \\
\text { patients }(n=90)\end{array}$ & $\begin{array}{c}\text { Hypertensive lacunar stroke } \\
\text { patients }(n=38)\end{array}$ \\
\hline Age, mean (SD), (years) & $58.6(12.2)$ & $56.2(11.9)$ & $64.1(11.2)$ \\
\hline Male sex, №. (\%) & 75 (58.6) & $52(57.8)$ & $23(60.5)$ \\
\hline \multicolumn{4}{|l|}{ Educational level, No. (\%) } \\
\hline Low & $40(31.3)$ & $22(24.4)$ & $18(47.4)$ \\
\hline Average & $42(32.8)$ & $33(36.7)$ & $9(23.7)$ \\
\hline High & $46(35.9)$ & $35(38.9)$ & $11(28.9)$ \\
\hline HADS total score, median (IQR) & $8(4-13)$ & $7(4-12)$ & $8.5(4-14)$ \\
\hline Diabetes mellitus, no. (\%) & $2(1.6)$ & $1(1.1)$ & $1(2.6)$ \\
\hline Hypercholesterolemia, no. (\%) & $55(44.0)$ & $30(34.1)$ & $25(67.6)$ \\
\hline Current smoking, no. (\%) & $26(20.3)$ & $14(15.6)$ & $12(31.6)$ \\
\hline $\mathrm{BMI}$, mean $\mathrm{SD},\left(\mathrm{kg} / \mathrm{m}^{2}\right)$ & $27.3(4.2)$ & $27.4(4.2)$ & $27.0(4.1)$ \\
\hline $\mathrm{SBP}$, mean (SD), (mmHg) & $145.5(17.9)$ & $145.4(16.4)$ & $145.7(21.4)$ \\
\hline DBP, mean (SD), (mmHg) & $84.2(11.7)$ & $84.9(10.4)$ & $82.4(14.3)$ \\
\hline
\end{tabular}

HADS, Hospital Anxiety and Depression Scale; IQR, interquartile range.

anformation about hypercholesterolemia was missing for three patients (two uncomplicated hypertensive patients and one hypertensive lacunar stroke patient).

\section{RESULTS}

\section{Participants}

Flow of participants is shown in Fig. 1. We included 112 uncomplicated hypertensive patients and 62 hypertensive lacunar stroke patients in the present study at baseline. Of these, 90 uncomplicated hypertensive patients and 38 lacunar stroke patients completed neuropsychological assessment and brain MRI at 4-year follow-up, which adds up to 128 patients in this study. The mean follow-up period was 4.04 years $(\mathrm{SD}=0.10)$. Included patients $(n=128)$ did not differ from the excluded patients $(n=167)$ in age or sex. Patients who completed follow-up $(n=128)$ did not differ from patients who only completed baseline $(n=46)$ regarding sex (male 58.6\% versus 56.5\%, respectively, $P=0.81)$, but they were younger $(58.6 \pm 12.2$ versus $65.1 \pm 13.5$, respectively, $P=0.003)$ and had better overall cognition at baseline $(P=0.014)$. Baseline characteristics for the overall group and separately for uncomplicated hypertensive patients and lacunar stroke patients are shown in Table 1. Decline in overall cognition was not different between these two patient groups $(P=0.720)$.

The number of patients with baseline presence and progression of each MRI marker of SVD are shown in Table 2. Three lacunar stroke patients had a recurrent stroke during follow-up, whereas none of the uncomplicated hypertensive patients had a stroke during follow-up.
For two patients, one baseline neuropsychological test score in the domain of executive function was missing. Therefore, for these patients the executive function decline score was composed of the remaining five tests in this domain. For three patients, the baseline Rey Auditory Verbal Learning Test was missing. As this test determines three out of four test scores of the memory domain, no reliable memory decline score could be formed for these two patients and consequently the overall cognition decline score was also missing. Brain MRI of two patients was of insufficient quality to determine progression of WMH. In addition, in one of these patients incident microbleeds could not be determined, because of insufficient quality of the $\mathrm{T}^{*}$ gradient echo image. As a result of these missing neuropsychological tests and missing MRI data, the number of patients in each analysis slightly differed.

At baseline three patients had a Rotterdam-Cambridge Cognitive Examination score less than 34, indicating possible dementia. At follow-up, besides these three patients, six other patients had a score less than 34 .

\section{MRI markers and cognitive decline}

In simple linear regression analyses, baseline periventricular WMH presence was not associated with cognitive decline, but the association between periventricular WMH progression and cognitive decline was significant (model 1; Table 3).

\begin{tabular}{|c|c|c|c|}
\hline MRI marker & $\begin{array}{l}\text { All patients } \\
(n=128)\end{array}$ & $\begin{array}{l}\text { Uncomplicated hypertensive } \\
\text { patients }(n=90)\end{array}$ & $\begin{array}{l}\text { Hypertensive lacunar } \\
\text { stroke patients }(n=38)\end{array}$ \\
\hline \multicolumn{4}{|l|}{ Baseline presence of cSVD } \\
\hline Extensive periventricular WMH, No. (\%) & $17(13.3)$ & $10(11.1)$ & $7(18.4)$ \\
\hline Extensive deep WMH, No. (\%) & $13(10.2)$ & $6(6.7)$ & $7(18.4)$ \\
\hline Microbleeds, №. (\%) & 25 (19.5) & 15 (16.7) & $10(26.3)$ \\
\hline Asymptomatic lacunes, No. (\%) & $40(31.3)$ & $21(23.3)$ & $19(50.0)$ \\
\hline Progression of subcortical WMH, No. $(\%)^{a}$ & $56(44.4)$ & $34(38.2)$ & $22(59.5)$ \\
\hline Incident microbleeds, No. $(\%)^{a}$ & $14(11.0)$ & $5(5.6)$ & $9(24.3)$ \\
\hline Incident lacunes, No. (\%) & $14(10.9)$ & $5(5.6)$ & $9(23.7)$ \\
\hline
\end{tabular}

CSVD, cerebral small vessel disease; WMH, white matter hyperintensities.

anformation about progression of periventricular and subcortical WMH was missing for two patients (one in each patient subgroup) and information about incident microbleeds was missing for one lacunar stroke patient. 
TABLE 3. Associations between white matter hyperintensities and overall cognitive decline

\begin{tabular}{|c|c|c|c|c|c|c|c|c|}
\hline & \multicolumn{4}{|c|}{ Periventricular WMH } & \multicolumn{4}{|c|}{ Subcortical WMH } \\
\hline & B & $95 \% \mathrm{Cl}$ & $P$ & $R^{2}$ change & B & $95 \% \mathrm{Cl}$ & $\boldsymbol{P}$ & $R^{2}$ change \\
\hline Model 1a. Simple regression analysis: baseline WMH & 0.15 & -0.07 to 0.38 & 0.185 & $1.4 \%$ & 0.23 & -0.02 to 0.48 & 0.066 & $2.7 \%$ \\
\hline Model $1 \mathrm{~b}$. Simple regression analysis: progression $\mathrm{WMH}$ & 0.27 & $0.11-0.43$ & 0.001 & $8.5 \%$ & 0.06 & -0.09 to 0.21 & 0.426 & $0.5 \%$ \\
\hline Model 2. Multivariable analysis & & & & a & & & & b \\
\hline Baseline WMH & 0.08 & -0.15 to 0.30 & 0.491 & $0.4 \%$ & 0.22 & -0.04 to 0.48 & 0.097 & $2.3 \%$ \\
\hline Progression WMH & 0.26 & $0.10-0.42$ & 0.002 & $7.4 \%$ & 0.03 & -0.13 to 0.18 & 0.735 & $0.1 \%$ \\
\hline Model 3. Multivariable analysis including covariates ${ }^{\mathrm{e}}$ & & & & c & & & & d \\
\hline Baseline WMH & 0.10 & -0.12 to 0.32 & 0.364 & $0.6 \%$ & 0.26 & -0.001 to 0.52 & 0.051 & $2.7 \%$ \\
\hline Progression WMH & 0.24 & $0.08-0.40$ & 0.004 & $5.6 \%$ & -0.009 & -0.16 to 0.14 & 0.910 & $0.0 \%$ \\
\hline
\end{tabular}

$B$, unstandardized regression coefficient; $\mathrm{Cl}$, confidence interval; $R^{2}$, coefficient of determination; WMH, white matter hyperintensities.

Total $R^{2}$ of the model $=8.9 \%$.

${ }^{\mathrm{b}}$ Total $R^{2}$ of the model $=2.8 \%$.

'Total $R^{2}$ of the model $=25.1 \%$.

Total $R^{2}$ of the model $=21.0 \%$.

eIncluding age, sex, educational level, HADS total score, patient group, baseline cognition.

In multivariable regression analyses, periventricular WMH progression remained significantly associated with cognitive decline, independent of baseline WMH presence (model 2; Table 3) and also additionally independent of age, sex, educational level, HADS total score, patient group, and baseline cognition (model 3; Table 3). There were no vascular risk factors included in the final model because there were no associations with $P<0.10$ between any of the vascular risk factors and overall cognitive decline in simple linear regression analyses. In this final multivariable model 3 , baseline periventricular WMH only explained $0.6 \%$ of variance in cognitive decline, whereas progression of periventricular WMH explained 5.6\%.

For both baseline and progression of subcortical WMH, no significant associations were found in any of the statistical models. Although nonsignificant, proportions of explained variance of cognitive decline were higher for baseline subcortical WMH presence than for WMH progression (Table 3). For baseline as well as progression of microbleeds or lacunes, none of the associations were significant and $R^{2}$ s were comparable for baseline presence and progression of the marker (Table 4).

When performing model 2 for both patient groups separately, results were similar to the results in the total group. The association between progression of periventricular WMH and cognitive decline was significant for both uncomplicated hypertensive patients and lacunar stroke patients $[B(95 \% \mathrm{CI})=0.24(0.03$ to 0.44$), P=0.026$, and $B(95 \% \mathrm{CI})=0.36(0.08$ to 0.65$), P=0.015$, respectively], whereas the associations between baseline periventricular WMH and cognitive decline were not significant in both patient groups. Associations between cognitive decline and the other MRI markers (subcortical WMH, microbleeds, and lacunes), both baseline and progression, were all nonsignificant in both patient groups.

\section{MRI markers and decline in separate cognitive domains}

In simple linear regression analyses between each of the vascular risk factors and cognitive decline, associations with $P<0.10$ were found between BMI and decline in executive function and between smoking and decline in information processing speed. These factors were included in the respective multivariable regression analyses.

Multivariable regression analyses, with correction for age, sex, educational level, HADS total score, patient group, baseline cognition of the corresponding cognitive domain, and vascular risk factors (as explained above), showed significant associations between executive functioning and progression of periventricular WMH, baseline presence

TABLE 4. Associations between microbleeds and lacunes and overall cognitive decline

\begin{tabular}{|c|c|c|c|c|c|c|c|c|}
\hline & \multicolumn{4}{|c|}{ Microbleeds } & \multicolumn{4}{|c|}{ Lacunes } \\
\hline & $B$ & $95 \% \mathrm{Cl}$ & $P$ & $R^{2}$ change & $\boldsymbol{B}$ & $95 \% \mathrm{Cl}$ & $P$ & $R^{2}$ change \\
\hline Model 1a. Simple regression analysis: baseline marker & 0.13 & -0.05 to 0.32 & 0.160 & $1.6 \%$ & 0.13 & -0.03 to 0.29 & 0.109 & $2.1 \%$ \\
\hline Model $1 \mathrm{~b}$. Simple regression analysis: progression marker & 0.15 & -0.10 to 0.41 & 0.229 & $1.2 \%$ & 0.18 & -0.05 to 0.41 & 0.126 & $1.9 \%$ \\
\hline Model 2. Multivariable analysis & & & & a & & & & b \\
\hline Baseline marker & 0.12 & -0.08 to 0.31 & 0.251 & $1.1 \%$ & 0.12 & -0.04 to 0.28 & 0.139 & $1.8 \%$ \\
\hline Progression marker & 0.11 & -0.15 to 0.37 & 0.390 & $0.6 \%$ & 0.17 & -0.07 to 0.40 & 0.161 & $1.6 \%$ \\
\hline Model 3. Multivariable analysis including covariates $^{\mathrm{e}}$ & & & & c & & & & d \\
\hline Baseline marker & 0.14 & -0.06 to 0.33 & 0.168 & $1.3 \%$ & 0.10 & -0.06 to 0.26 & 0.222 & $1.0 \%$ \\
\hline Progression marker & 0.08 & -0.18 to 0.34 & 0.541 & $0.3 \%$ & 0.17 & -0.06 to 0.40 & 0.152 & $1.4 \%$ \\
\hline
\end{tabular}

$B$, unstandardized regression coefficient; $\mathrm{Cl}$, confidence interval; $R^{2}$, coefficient of determination.

Total $R^{2}$ of the model $=2.3 \%$

${ }^{b}$ Total $R^{2}$ of the model $=3.6 \%$.

'Total $R^{2}$ of the model $=20.1 \%$

${ }^{\mathrm{d}}$ Total $R^{2}$ of the model $=20.4 \%$.

Including age, sex, educational level, HADS total score, patient group, baseline cognition. 
of subcortical WMH, and baseline presence of lacunes. No significant associations were found between information processing speed or memory and any of the MRI markers. For tables with results, please see supplemental digital content, http://links.lww.com/HJH/A738.

\section{DISGUSSION}

Our results show that progression of periventricular WMH over 4 years is associated with cognitive decline, especially in the domain of executive functioning, in patients with hypertension. Furthermore, progression is more important in predicting cognitive decline than periventricular $\mathrm{WMH}$ already present at baseline. We could not show associations between progression of subcortical WMH, microbleeds, or lacunes and overall cognitive decline.

Other studies also showed that progression of periventricular WMH is associated with cognitive decline. Van den Heuvel et al. [11]. showed periventricular WMH progression to be related with decline in executive functioning in a nondemented elderly population and Van Dijk et al. [10]. showed it to be related with decline in general cognitive function and information processing speed in a populationbased cohort study. In agreement with our study, both studies also found no associations between progression of subcortical WMH and cognitive decline. Most other studies that showed progression of WMH to be related with cognitive decline did not differentiate between periventricular and subcortical WMH $[12,13]$. In a cross-sectional study, De Groot et al. [2]. found that the degree of periventricular WMH was associated with cognitive impairment, whereas the degree of subcortical WMH was not. They suggested that subcortical WMH probably disrupt short cortico-cortical connections, while periventricular WMH are more likely to disrupt long associating tracts that connect more distant cortical areas. As the performance on neuropsychological tests is more likely to depend on the connection between many cortical areas, this could explain the reported difference between periventricular and subcortical WMH in associations with cognition.

We showed that progression of periventricular WMH explained $5.6 \%$ of variance in cognitive decline, whereas baseline periventricular WMH only explained $0.6 \%$ of variance. All other covariates in the model, including age, together explained $18.3 \%$. Therefore, we think that preventing progression of periventricular WMH can make a relevant difference in the prevention of cognitive decline. However, most of the variance in cognitive decline is unexplained, so there are still many more factors predicting cognitive decline.

We could not find significant associations between occurrence of new microbleeds or lacunes and cognitive decline. A few other studies have shown associations between incident lacunes and cognitive decline $[10,16,17]$. These studies not only had a larger sample size, but also a higher percentage of patients with incident lacunes, ranging from 12 to $18.6 \%$. In addition, these studies were performed in other populations. For example, one study took the presence of WMH as an inclusion criterion. As this is a predictor of future progression of SVD, this may explain the different results [16]. Regarding incident microbleeds, we could only find one other study which addressed its association with cognitive decline [18]. This study examined patients with cerebral autosomal dominant arteriopathy with subcortical infarcts and leukoencephalopathy and showed that an increase in number of microbleeds over 7 years was associated with cognitive decline. However, the number of microbleeds (mean number 3.5, range $0-40$ ) in these patients is much higher than in our population, which might explain the different results. Also, whether results found in patients with a genetic variant of cSVD, known for its progressive nature and strong association with cognitive decline, can be generalized to populations with common types of cSVD is questionable.

Studies have shown that active BP lowering might stop or delay the progression of WMH in patients with and without cerebrovascular disease [37,38]. In addition, a previous study has shown that BP is most strongly associated with periventricular WMH compared with subcortical WMH [39]. As our results show that progression of periventricular WMH is associated with cognitive decline, it suggests the importance of good BP control in patients with hypertension to prevent its progression. In our study, we did not have specific information about BP control during the 4 years of follow-up, so we could not examine its effect on progression of WMH. This is an important limitation of our study.

Another limitation of the study is the use of variable MRI field strength. In total, 107 of 128 patients (83.6\%) were scanned at a $1.5 \mathrm{~T}$ MRI scanner and 21 (16.4\%) patients, all lacunar stroke patients, at a 3T MRI. In all patients, the same scanner was used for baseline and follow-up. However, rating of progression in patients scanned at $3 \mathrm{~T}$ might be overestimated compared with $1.5 \mathrm{~T}$. We repeated the multivariable regression analyses in only those patients scanned at $1.5 \mathrm{~T}$. The association between progression of periventricular WMH and cognitive decline did not change. The second limitation is the mixed hypertensive population. To reach a relatively large sample with a substantial progression of cerebral SVD, we included both hypertensive patients with and without small vessel stroke. However, by including patient group as a confounder we corrected for the presence of a symptomatic stroke in medical history. In addition, we showed that results were similar in separate analyses for each patient group. Three lacunar stroke patients had a recurrent stroke during follow-up, which might have influenced cognitive decline. However, results did not change when we excluded these three patients from analyses (results not shown). Third, a visual scale was used to assess WMH presence and progression. The use of volumetric techniques might have been more sensitive. This could have led to an underestimation of the $R^{2}$ of presence or progression of WMH in the association with cognitive decline. In addition, an underestimation of cognitive decline might be caused by the higher dropout rate of older and cognitively worse patients. Despite these limitations, a major strength is the longitudinal design of our study with a 4-year follow-up period. In addition, all patients received extensive neuropsychological assessments, which included multiple tests in three cognitive domains.

In conclusion, we found that progression of periventricular WMH over 4 years is associated with cognitive 
decline in hypertensive patients, whereas we could not show an association between baseline periventricular WMH and cognitive decline. Therefore, these results show the importance of preventing progression of $\mathrm{WMH}$ in patients with hypertension. As studies have shown that active BP lowering might stop or delay the progression of WMH, future studies are needed to investigate if optimal $\mathrm{BP}$ control that minimizes progression of WMH in patients with hypertension, can also prevent cognitive decline. In our study, we could not show significant associations between progression of other MRI markers of SVD and overall cognitive decline over 4 years. As the proportion of patients with hypertension who developed new lacunes or microbleeds over time was relatively small, larger studies with a long follow-up period are needed to further investigate this.

\section{ACKNOWLEDGEMENTS}

\section{Conflicts of interest}

There are no conflicts of interest.

Sources of support: The project was supported by the 'Stichting de Weijerhorst' and has received funding from the European Union's Horizon 2020 research and innovation programme under grant agreement No 666881, SVDs@target.

\section{REFERENCES}

1. Iadecola C. Hypertension and dementia. Hypertension 2014; 64:3-5.

2. de Groot JC, de Leeuw F, Oudkerk M, van Gijn J, Hofman A, Jolles J, Breteler M. Cerebral white matter lesions and cognitive function: the Rotterdam Scan Study. Ann Neurol 2000; 47:145-151.

3. van der Flier WM, van Straaten EC, Barkhof F, Verdelho A, Madureira S, Pantoni L, et al. Small vessel disease and general cognitive function in nondisabled elderly the LADIS study. Stroke 2005; 36:2116-2120.

4. Carey CL, Kramer JH, Josephson SA, Mungas D, Reed BR, Schuff N, et al. Subcortical lacunes are associated with executive dysfunction in cognitively normal elderly. Stroke 2008; 39:397-402.

5. van Norden AG, van den Berg HA, de Laat KF, Gons RA, van Dijk EJ, de Leeuw FE. Frontal and temporal microbleeds are related to cognitive function: the Radboud University Nijmegen Diffusion tensor and Magnetic resonance Cohort (RUN DMC) study. Stroke 2011; 42:3382-3386

6. Werring DJ, Frazer DW, Coward LJ, Losseff NA, Watt H, Cipolotti L, et al. Cognitive dysfunction in patients with cerebral microbleeds on $\mathrm{T}^{*}$ weighted gradient-echo MRI. Brain 2004; 127:2265-2275.

7. Prins ND, van Dijk EJ, den Heijer T, Vermeer SE, Jolles J, Koudstaal PJ, et al. Cerebral small-vessel disease and decline in information processing speed, executive function and memory. Brain 2005; 128:20342041.

8. Pavlovic AM, Pekmezovic T, Tomic G, Trajkovic JZ, Sternic N. Baseline predictors of cognitive decline in patients with cerebral small vessel disease. J Alzheimers Dis 2014; 42:S37-S43.

9. Jokinen H, Kalska H, Ylikoski R, Madureira S, Verdelho A, Van Der Flier WM, et al., LADIS group. Longitudinal cognitive decline in subcortical ischemic vascular disease: the LADIS Study. Cerebrovasc Dis 2009; 27:384-391.

10. van Dijk EJ, Prins ND, Vrooman HA, Hofman A, Koudstaal PJ, Breteler MM. Progression of cerebral small vessel disease in relation to risk factors and cognitive consequences: Rotterdam scan study. Stroke 2008; 39:2712-2719

11. Van den Heuvel D, Ten Dam V, De Craen A, Admiraal-Behloul F, Olofsen $\mathrm{H}$, Bollen $\mathrm{E}$, et al. Increase in periventricular white matter hyperintensities parallels decline in mental processing speed in a nondemented elderly population. J Neurol Neurosurg Psychiatry 2006; 77:149-153.

12. Longstreth W, Arnold AM, Beauchamp NJ, Manolio TA, Lefkowitz D, Jungreis $\mathrm{C}$, et al. Incidence, manifestations, and predictors of worsening white matter on serial cranial magnetic resonance imaging in the elderly the cardiovascular health study. Stroke 2005; 36:56-61.

13. Schmidt R, Ropele S, Enzinger C, Petrovic K, Smith S, Schmidt H, et al. White matter lesion progression, brain atrophy, and cognitive decline: the Austrian stroke prevention study. Ann Neurol 2005; 58:610-616.

14. Yoon B, Shim YS, Cheong H-K, Hong Y-J, Lee K-S, Park KH, et al. White matter hyperintensities in mild cognitive impairment: clinical impact of location and interaction with lacunes and medial temporal atrophy. J Stroke Cerebrovasc Dis 2014; 23:e365-e372.

15. Soriano-Raya JJ, Miralbell J, López-Cancio E, Bargalló N, Arenillas JF, Barrios $\mathrm{M}$, et al. Deep versus periventricular white matter lesions and cognitive function in a community sample of middle-aged participants. J Int Neuropsychol Soc 2012; 18:874-885.

16. Jokinen H, Gouw A, Madureira S, Ylikoski R, van Straaten E, van Der Flier W, et al., LADIS Study Group. Incident lacunes influence cognitive decline: the LADIS study. Neurology 2011; 76:1872-1878.

17. Longstreth W, Dulberg C, Manolio TA, Lewis MR, Beauchamp NJ, O'Leary $\mathrm{D}$, et al. Incidence, manifestations, and predictors of brain infarcts defined by serial cranial magnetic resonance imaging in the elderly: the Cardiovascular Health Study. Stroke 2002; 33:2376-2382.

18. Liem M, Oberstein SL, Haan J, van der Neut I, Ferrari M, van Buchem M, et al. MRI correlates of cognitive decline in CADASIL A 7-year follow-up study. Neurology 2009; 72:143-148.

19. Veglio F, Paglieri C, Rabbia F, Bisbocci D, Bergui M, Cerrato P. Hypertension and cerebrovascular damage. Atherosclerosis 2009; 205:331-341.

20. Verhaaren BF, Vernooij MW, de Boer R, Hofman A, Niessen WJ, van der Lugt A, Ikram MA. High blood pressure and cerebral white matter lesion progression in the general population. Hypertension 2013; 61:1354-1359.

21. Henskens LH, van Oostenbrugge RJ, Kroon AA, De Leeuw PW, Lodder $\mathrm{J}$. Brain microbleeds are associated with ambulatory blood pressure levels in a hypertensive population. Hypertension 2008; 51:62-68.

22. Huijts M, Duits A, van Oostenbrugge RJ, Kroon AA, De Leeuw PW, Staals J. Accumulation of MRI markers of cerebral small vessel disease is associated with decreased cognitive function. A study in first-ever lacunar stroke and hypertensive patients. Front Aging Neurosci 2013; 5:72.

23. De Jong G, Kessels F, Lodder J. Two types of lacunar infarcts further arguments from a study on prognosis. Stroke 2002; 33:2072-2076.

24. Verhage F. Intelligentie en leeftijd: onderzoek bij Nederlanders van twaalf tot zevenenzeventig jaar. Assen: Van Gorcum; 1964.

25. Fazekas F, Chawluk JB, Alavi A, Hurtig HI, Zimmerman RA. MR signal abnormalities at $1.5 \mathrm{~T}$ in Alzheimer's dementia and normal aging. AJR Am J Roentgenol 1987; 149:351-356.

26. Wardlaw JM, Smith EE, Biessels GJ, Cordonnier C, Fazekas F, Frayne R, et al. Neuroimaging standards for research into small vessel disease and its contribution to ageing and neurodegeneration. Lancet Neurol 2013; 12:822-838.

27. Prins N, van Straaten E, van Dijk E, Simoni M, van Schijndel R, Vrooman $\mathrm{H}$, et al. Measuring progression of cerebral white matter lesions on MRI: visual rating and volumetrics. Neurology 2004; 62:1533-1539.

28. Uiterwijk R, Huijts M, Staals J, Duits A, Gronenschild E, Kroon AA, et al. Subjective cognitive failures in patients with hypertension are related to cognitive performance and cerebral microbleeds. Hypertension 2014; 64:653-657.

29. Golden CJ. Stroop Colour and Word Test. Chicago (IL): Stoelting; 1978

30. Reitan R. Trail Making Test: Manual for administration, scoring and interpretation. Bloomington: Indiana University; 1956.

31. Luteyn F. Een nieuwe verkorte GIT. Dutch J Psychol 1966; 2:675-682.

32. Lezak MD, Howieson DB, Loring DW. Neuropsychological assessment. New York: Oxford University Press; 2004.

33. Wechsler D. WAIS III, nederlandstalige bewerking: technische handleiding. Lisse: Swets Test Publishers; 2001.

34. Brand N, Jolles J. Learning and retrieval rate of words presented auditorily and visually. J Gen Psychol 1985; 112:201-210.

35. de Koning I, van Kooten F, Koudstaal PJ, Dippel DW. Diagnostic value of the Rotterdam-CAMCOG in poststroke dementia.J Neurol Neurosurg Psychiatry 2005; 76:263-265.

36. Spinhoven PH, Ormel J, Sloekers PP, Kempen GI, Speckens AE, van Hemert AM. A validation study of the Hospital Anxiety and Depression Scale (HADS) in different groups of Dutch subjects. Psychol Med 1997; $27: 363-370$. 
37. Dufouil C, Chalmers J, Coskun O, Besancon V, Bousser M-G, Guillon P, et al., PROGRESS MRI Substudy Investigators. Effects of blood pressure lowering on cerebral white matter hyperintensities in patients with stroke the PROGRESS (Perindopril Protection Against Recurrent Stroke Study) magnetic resonance imaging substudy. Circulation 2005; 112:1644-1650.

\section{Reviewers' Summary Evaluations}

\section{Referee 1}

This is a tidy study that adds to the growing body of evidence for an association of middle-aged hypertension and cognitive decline. In a relatively small $(n=174)$ clinic population of two mildly hypertensive patient groups, with and without minor lacunar stroke, the authors report that progression of periventricular white matter lesions is related to cognitive decline over 4 years. The study also highlights the complexities of such analysis, uncertainty over clinical significance of small changes in continuous
38. Firbank MJ, Wiseman RM, Burton EJ, Saxby BK, O'Brien JT, Ford GA. Brain atrophy and white matter hyperintensity change in older adults and relationship to blood pressure. J Neurol 2007; 254:713-721.

39. Henskens LH, Kroon AA, van Oostenbrugge RJ, Gronenschild EH, Hofman PA, Lodder J, de Leeuw PW. Associations of ambulatory blood pressure levels with white matter hyperintensity volumes in hypertensive patients. J Hypertens 2009; 27:1446-1452.

neuropsychological measures, and the pressing need for randomized clinical endpoint studies in this area.

\section{Referee 2}

This longitudinal study provides an important piece of information about the association between periventricular white matter hyperintensities (WMH) and cognitive decline in hypertensive patients with previous lacunar stroke. Baseline periventricular WMH were not significantly associated with cognitive decline, but progression of periventricular WMH was associated with cognitive decline during the 4 years of follow-up. 